\title{
Occurrence of benzotriazoles in the rivers Main, Hengstbach, and Hegbach (Germany)
}

\author{
Aliz Kiss • Elke Fries
}

Published online: 16 July 2009

(C) Springer-Verlag 2009

\section{Erratum to: Environ Sci Pollut Res DOI 10.1007/s11356-0179-4}

Unfortunately, the first part of fig. 2 was published with an error. The correct version of the first part is given here.

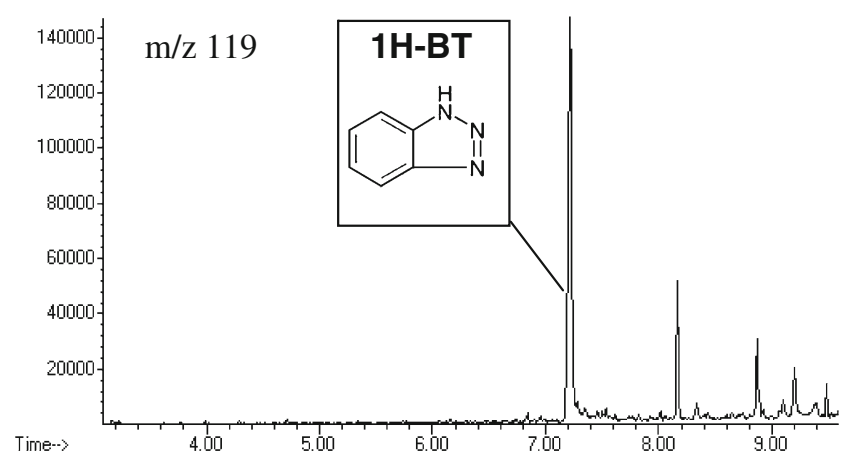

Fig. 2 Selective ion chromatograms of quantification ions $\mathrm{m} / z 119$ for 1H-BT, $m / z 104$ for 5Me-BT and 4Me-BT, and $m / z 118$ for surrogate standard (5,6-dimethyl-1H-benzotriazole-monohydrate) resulted from the SPE/GC-MC analysis of a river water extract taken from Hengstbach River with signals for BT and retention times (in minutes)

The online version of the original article can be found at http://dx.doi. org/10.1007/s11356-0179-4.

A. Kiss $\cdot$ E. Fries $(\bowtie)$

Institute of Environmental System Research,

University of Osnabrueck,

Barbarastraße 12,

49076 Osnabrueck, Germany

e-mail: fries@usf.uos.de 